\title{
EL LLAMADO TEMPLO DE JÚPITER DE CLUNIA: PROPUESTA DE RESTITUCIÓN
}

\author{
POR \\ M. ÁNGELES GUTIÉRREZ BEHEMERID \\ Universidad de Valladolid \\ EVA SUBÍAS PASCUAL \\ Universitat Rovira i Virgili
}

PALABRAS CLAVE: Arquitectura romana. Templos romanos. Estudio arquitectónico. Clunia (Peñalba de Castro, Burgos). Siglo I d.C.

KEY WORDS: Roman architecture. Roman temples. Architectonic analysis. Clunia (Peñalba de Castro, Burgos). $1^{\text {st }}$ century $\mathrm{AD}$.

\section{RESUMEN}

En este trabajo se propone una restitución del alzado del llamado templo de Júpiter de Clunia a partir de diferentes elementos arquitectónicos relacionados entre sí con un criterio estilístico y dimensional. Se valoran también algunos rasgos tipológicos de la planta, todo ello con el objeto de intentar enmarcar cronológicamente su construcción y al mismo tiempo de establecer una relación con otros templos conocidos en la parte occidental del Imperio romano.

\section{SUMMARY}

This paper proposes the restoration of the elevation of the so-called Temple of Jupiter in Clunia, based on different architectural elements, inter-related by a stylistic and dimensional criterion. Some typological traces of the plan are also evaluated, while establishing a relationship with other known temples in the western part of the Roman Empire.

El llamado templo de Júpiter de Clunia, como correspondía a su carácter de templo principal de la ciudad, ocupaba una posición dominante respecto a los edificios de su entorno: se ubicaba en el extremo sur del foro, elevado sobre un alto podio. En la actualidad lo único que se mantiene en pie de esta construcción es el conglomerado de argamasa y piedras que constituía el relleno del podio.

La identificación de estos restos con el templo de Júpiter comienza a partir de las excavaciones que I. Calvo realizó en la ciudad en los años 1915 y 1916, quien en el lugar denominado «El Torreón» asoció los restos de la gran construcción con una fortificación medieval. Con posterioridad, dichos restos se pondrían en relación con el templo de Júpiter $^{1}$. Las excavaciones realizadas en 1972 y 1973

1 I. Calvo, «Excavaciones en Clunia», MJSEA., vol. III, Madrid, 1916 por P. de Palol se orientaron básicamente a la limpieza y consolidación de la estructura del podio haciéndose evidente, entonces, la existencia de dos escaleras laterales que daban acceso a la parte superior. Se publicaron después sus resultados en algunos trabajos sobre el templo, si bien centrados fundamentalmente en el análisis de su planta ${ }^{2}$.

Su dedicación a Júpiter se viene comúnmente aceptando ya que su culto parece estar atestiguado tanto a través de textos ${ }^{3}$ como de testimonios epigráficos ${ }^{4} \mathrm{e}$, incluso, escultóricos ${ }^{5}$. Se ha señalado, en algunas ocasiones, que pudiera tratarse de un capitolio ${ }^{6}$, sin embargo, esta atribución no se puede deducir directamente a partir de los restos arquitectónicos. En efecto, los matices religiosos introducidos por la aparición del culto imperial y por los cambios de estatuto administrativo de las ciudades obligan a una lectura prudente de la tipología y de la organización espacial de los lugares de culto. En este sentido cabe señalar que además del culto a Júpiter, en Clunia tenía un lugar destacado el culto a Roma y Augusto, tal como testimonia la mención de su sacerdocio ${ }^{7}$.

\section{ELEMENTOS ARQUITECTÓNICOS DEL TEMPLO}

Apenas contamos con referencias en lo que respecta al lugar de hallazgo o procedencia de los elementos arquitectónicos que se proponen para el templo. Existen breves noticias de I. Calvo a propósito de algunos hallazgos efectuados en una excava-

${ }^{2}$ P. de Palol, Clunia 0. Clunia Sulpicia, ciudad romana. Su historia y su presente, Burgos, 1991, p.24.

${ }^{3}$ Suetonio, en su biografía sobre Galba, menciona la existencia de un templo a Júpiter: P. de Palol, cit. nota 2, p. 16.

${ }^{4}$ P. de Palol, «Los edificios de culto en la ciudad de Clunia», Anas, 2-3, 1989-1990, pp. 38-39.

${ }^{5}$ Se trata de una estatua de Júpiter, hoy desaparecida, de la que Huidobro publicaba una fotografía y que reproduce Palol, cit. nota 2, p. 29 y lám. XXXVI.

${ }_{6}$ M. Bendala, «Capitolia Hispaniarum», Anas, 2-3, 1989 1990, pp. 13 y 22; P. de Palol, cit. nota 4, pp. 38-39.

7 P. de Palol y J. Vilella, Clunia II. La epigrafía de Clunia, Madrid, 1987, p. 31. 
ción realizada en 1915, la cual, sin embargo, plantea numerosas dudas ${ }^{8}$. En los sondeos llevados a cabo por P. de Palol tampoco aparecieron elementos decorativos o arquitectónicos del templo ${ }^{9}$.

Son, por tanto, piezas sin un contexto arqueológico claro. Algunos fragmentos se encontraban depositados en la antigua hospedería. Existen, asimismo, piezas reutilizadas en la propia ermita del Castro y en alguna casa de Peñalba. Otras se han recuperado recientemente con ocasión de los trabajos que se están efectuando en el yacimiento en los últimos años. Hay que hacer notar, sin embargo, el hecho de que alguna pieza que se incluye como perteneciente al templo - un fragmento de cornisa de dentículos, en concreto- es mencionada por Palol como procedente del llamado aedes augusti ${ }^{10}$. No obstante, se ha podido comprobar que sus dimensiones resultan más acordes con el templo.

Estos restos dispersos han sido sometidos, en primer lugar, a un detallado análisis que pone de manifiesto su coherencia estilístico-tipológica y su pertenencia a un grupo cronológicamente homogéneo. Seguidamente se han ponderado sus dimensiones y relaciones proporcionales de modo que se ha considerado que podían haber pertenecido a un mismo edificio. Pero el dato clave que ha servido en última instancia para establecer su pertenencia al templo de Júpiter radica en que todos los elementos guardan una relación adecuada con las dimensiones que ofrece un fuste, de $97 \mathrm{~cm}$ de diámetro aproximadamente, aparecido junto al templo. Hasta la fecha, ninguna otra estructura de la ciudad, siquiera la basílica o el llamado «templo tripartito», presenta soportes que encajen con estas dimensiones. El templo, en cambio, no sólo admite columnas de este tamaño sino que, como se verá, éstas resuelven su fachada.

${ }^{8}$ Calvo menciona que «en el lugar denominado el Torreón, a dos metros de profundidad salió una gruesa capa de ceniza y debajo de esas cenizas encontramos una escalera de piedra sillar de $7 \mathrm{~m}$ de extensión y, caídos sobre sus cuatro gradas o peldaños, había seis fustes de otras tantas columnas de orden toscano», restos arquitectónicos que, como menciona después, fueron saqueados: I. Calvo, «En las ruinas de Clunia», $R A B M, 20,1916$, p. 103 . Esta referencia plantea dudas en cuanto al lugar exacto del hallazgo puesto que éste se encontraría a dos metros de profundidad, lo que descarta el podio del templo, por aquél entonces prácticamente al descubierto, pero la referencia a la escalera por el contrario, parece muy acorde con las dimensiones del templo.

${ }_{9}$ P. de Palol, cit. nota 4, pp. 45-48: «No hemos dispuesto, tampoco, de ningún elemento ornamental completo; ni restos de fustes de columnas, ni de capiteles o frisos del entablamento.

${ }_{10}$ En el capítulo «Excavaciones en el Foro Romano de Clunia. 1968», del volumen P. de Palol, cit. nota 2, p. 170, se señala un «fragmento de friso de dados de la cornisa superior de dimensiones bastante considerables» que no va acompañado de documentación gráfica.
Los materiales que han posibilitado la restitución son varios fragmentos de capitel corintio junto con algunas ménsulas, casetones y dentículos a los que se añaden el fragmento de fuste citado, una pieza de apoyo de la basa que corrobora la medición del diámetro y tres más de acrótera ${ }^{11}$. A estos restos arquitectónicos se añaden los datos que aporta la molduración del podio, tanto de la parte inferior como del coronamiento. La moldura inferior del podio, en gran parte restaurada, se puede seguir a lo largo de casi todo el perímetro. Caída a un lado, se conserva una losa que corresponde al coronamiento de modo que es posible la reconstrucción completa del perfil. Dicha moldura consiste en una kyma recta entre dos listeles. En el zócalo, apoyado sobre un plinto, se repite la kyma recta -invertida en este caso-, acompañada de una doble sucesión de listeles. Además, el fragmento de coronamiento presenta en la cara superior un resalte cuadrado que ha permitido formular la hipótesis de restitución de unos canceles para la plataforma frontal.

No se conocen las basas. Entre todas las que pertenecen al yacimiento no se encuentra una modalidad que por sus características y dimensiones sea la apropiada para integrarse dentro de este conjunto. Calvo, en el artículo citado, mencionaba la aparición de columnas de orden toscano; no creemos, sin embargo, que el templo poseyera basas de esas características. Nos inclinamos a pensar que fueran áticas, con unos rasgos similares a las de la basílica, aunque de dimensiones ligeramente superiores. Según este paralelo, el perfil presentaría dos toros ligeramente desiguales separados por una breve escocia que apoyarían directamente sobre el estilobato.

El fragmento de fuste aparece liso, si bien cabe la posibilidad de que presentara un revestimiento de estuco y sus acanaladuras estuvieran realizadas en ese material.

Los fragmentos de capitel, a excepción del que ha servido de base para determinar sus proporciones generales, son de pequeñas dimensiones. Aun así, permiten una aproximación bastante real al modelo y dimensiones del tipo de capitel corintio que debió de utilizarse en el templo ya que dos de los fragmentos son lo suficientemente explícitos como para permitir su restitución. El ejemplar de mayores dimensiones corresponde a parte del segundo registro, en concreto, al arranque de los cálices de los cau-

11 Se trata, en concreto, de un fragmento de fuste, tres de capitel corintio, dos correspondientes a las coronas y uno a la flor del ábaco. De la cornisa: cuatro fragmentos de dentículos, seis de ménsulas, tres de ellas bastante completas, junto con cinco casetones. Además, una acrótera angular y dos pequeños fragmentos. 
lículos y al comienzo del cáliz central. Se trata de un capitel realizado en dos bloques que se unirían por encima de la orla de los caulículos. El segundo fragmento corresponde, asimismo, al cáliz de los caulículos y ofrece los mismos rasgos que el ejemplar anterior. Finalmente, un fragmento de flor de ábaco, con unas características específicas, que encaja perfectamente con esta modalidad de capitel.

Los materiales de mayor entidad corresponden a la cornisa. Se trata de un conjunto amplio y uniforme que ha permitido su restitución puesto que existen elementos suficientes para completar su perfil. Éste, de abajo arriba, comprende un talón liso que serviría de unión con el friso, rematado en un pequeño baquetón. A continuación, un listel y la zona correspondiente a los dentículos, repitiéndose la misma molduración que en la zona inferior. En el registro medio se sitúan los casetones y las ménsulas alternando. Una corona lisa seguida de la sima perfilada en una kyma recta remata la cornisa en la parte superior.

Se desconocen, al menos por el momento, restos arquitectónicos que se puedan relacionar sin lugar a dudas con el arquitrabe o con el friso del templo. Podemos aventurar que se trataría de un arquitrabe a tres bandas, de altura decreciente hacia la base, puesto que éste es el esquema que se impondrá desde fines del s. I a.C. tal y como se puede comprobar a través de diferentes ejemplos: la Basílica Emilia, el templo de Apolo in circo, el de Mars Ultor, el templo de Vienne o la Maison Carrée. En todos los casos, cada una de las fasciae está coronada por un kymation $^{12}$. Es posible que el arquitrabe cluniense no presentara decoración ya que, como se ha visto en la cornisa, la tónica dominante es la de no ofrecer motivos decorativos en los diferentes perfiles.

En lo que al friso respecta, existen en el yacimiento algunos fragmentos con decoración vegetal - guirnaldas, concretamente- si bien no puede asegurarse su adscripción a este edificio. Se trata de piezas de reducidas dimensiones y bastante deterioradas que imposibilitan un análisis estilístico detallado lo que permitiría, al menos, establecer una relación cronológica con los restantes elementos del templo. Los fragmentos de mayor entidad, igualmente escasos, corresponden a un momento posterior, plena época julio-claudia o comienzos de la flavia. En cualquier caso, debería tratarse de un friso decorado con guirnaldas de acanto ya que es la decoración más extendida en los momentos en los

${ }_{12}$ P.Gros, Aurea Templa. Recherches sur l'architecture religieuse a Rome à l'époque d'Auguste, Rome, 1976 pp. 229. 230; Idem, «Les Temples Géminés de Glanum», RAN, 14, 1981, pp. 143-144; P. Pensabene, «La decorazione architettonica di Cherchel: cornici, architravi, soffiti, basi e pilastri», Supl. RM, 25, 1983, p. 137. que se sitúa la construcción del templo y la que muestran la mayoría de los ejemplos mencionados a propósito del arquitrabe.

Por último, además de las piezas indicadas, se ha encontrado una acrótera angular, bastante completa, y otros dos pequeños fragmentos correspondientes a sendos remates superiores.

\section{ANÁLISIS DE LOS ELEMENTOS ARQUITEC- TÓNICOS}

El análisis pormenorizado de los diferentes elementos arquitectónicos que conforman el templo permite su integración, tanto estilística como formal y cronológica, dentro de las corrientes artísticas que dominan en el imperio durante la época augustea y los primeros momentos de la tiberiana, tal y como se verá a continuación. Los elementos claves a la hora de obtener los datos más relevantes para determinar su filiación estilística y cronológica son los que proporcionan la moldura del podio, el acanto de los capiteles y el perfil de la cornisa.

En lo que al podio respecta (fig. 1), las molduras que configuran su perfil son muy sencillas y están en relación con la simplicidad que ofrecen todos sus elementos. Como ya se ha señalado, la moldura principal consiste, tanto en el coronamiento como en el zócalo, en una kyma recta, en posición invertida en este último, acompañada por listeles. El empleo de la kyma recta se remonta a finales del s. II a.C., como consecuencia de la recesión que sufre la utilización de la kyma reversa tanto en Roma como en Italia a partir de esos momentos, si bien su presencia se mantiene en algunos lugares, en la Narbonense, por ejemplo, hasta los comienzos de la época augustea ${ }^{13}$.

Es frecuente que la kyma recta se acompañe tanto en el zócalo como en el coronamiento de otras molduras. En este sentido, las molduras de la parte superior del podio van a ir adquiriendo paulatinamente una mayor complejidad ya que su configuración reflejará la estructura de una auténtica cornisa. No hay, sin embargo, una regla fija en cuanto al tipo de molduras que pueden acompañar a la kyma recta dado que éstas pueden variar de unos edificios a otros. El perfil del zócalo estará en consonancia, a su vez, con el del coronamiento desde el momento que las molduras principales se repiten en ambos casos, si bien en el zócalo habrá molduras que hagan referencia a su función específica, tales como el

${ }^{13}$ P. Gros, «Pour une chronologie des arcs de trioumphe de Gaule Narbonnaise (à propos de l'arc de Glanum», $G a$ llia, 37, 1979, p. 64. 

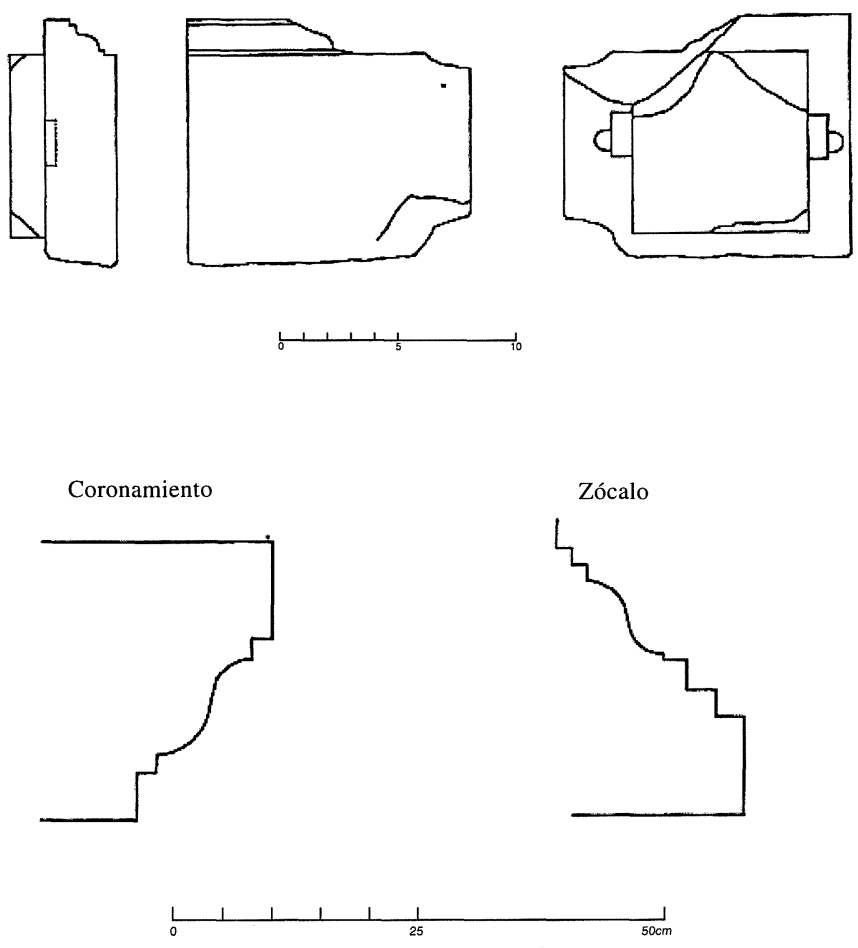

Fig. 1.-Elementos pertenecientes al podio.

plinto o el toro ${ }^{14}$. Vemos como en el caso cluniense se cumplen también estas premisas ya que se repite exactamente la misma molduración en la base y en el coronamiento.

En cualquier caso, la kyma recta se impone como elemento central de un gran número de perfiles cuya datación se sitúa entre la época tardorrepublicana y la augustea. Así, por ejemplo, en el templo del Divo Iulio, en el de Apolo in circo, en el de Mars Ultor o en la Maison Carrée entre otros ${ }^{15}$. En la Península Ibérica encontramos dos ejemplos que participan de similares características en sus respectivos podios y de análoga simplicidad de molduras. Se trata, en concreto, del templo de Barcelona ${ }^{16} \mathrm{y}$ del de Diana en Mérida ${ }^{17}$; en ambos casos y, en especial en el emeritense, con una datación próxima a la del templo Clunia.

${ }_{14}$ M. Montagna, La decorazione architettonica del Tempio del Divo Giulio nel Foro Romano, Roma 1973, p. 265 , láms. VI c y VII a.

15 R. Amy y P. Gros, La Maison Carrée de Nîmes, Supl. Gallia XXXVIII, 1979, pp. 119-121.

${ }_{16}$ M.A. Gutiérrez Behemerid, «El Templo de Barcino. Análisis de la decoración arquitectónica», Cuadernos de Arquitectura Romana, I, 1992, lám. I,3.

17 J.M. Álvarez Martínez, «El Templo de Diana», Cuadernos de Arquitectura Romana, I, 1992, láms. 4 y 5.
A partir de los fragmentos de capitel recuperados se ha podido restituir el modelo de capitel corintio utilizado en el templo (figs. 2 y 3). El kalathos muestra dos coronas de hojas de acanto correspondientes aproximadamente a la mitad de la altura total del capitel. La articulación de la hoja se efectuaría en cuatro o cinco lóbulos de hojitas lanceoladas, con zonas de sombra en forma de gota inclinada, seguida de un triángulo curvo en el punto de contacto de las digitaciones. Una nervadura central, en resalte, recorrería la hoja verticalmente acom-. pañada de surcos arqueados, convergentes hacia la parte inferior de la misma. Los caulículos cortos, con estrías oblicuas y ligeramente inclinados, finalizarían en una corona de sépalos. Sus cálices, formados por dos hojas de acanto de perfil, reproducirían, como es lo habitual, el mismo tipo de hojas de là base. En dos de las piezas se aprecia, concretamente, el motivo de gota seguido de dos triángulos equiláteros en la unión de las distintas digitaciones. Probablemente las volutas y las hélices serían estrechas, de sección cóncava y con los márgenes en resalte, rematándose en espiral. El cáliz central, del que se conserva su arranque en uno de los fragmentos, parece componerse de dos pequeñas hojitas de perfil, articuladas en pequeños lóbulos; de su interior brotaría el tallo para la flor del ábaco. Ésta muestra una corona formada por varias hojitas, con un pistilo ondulado en el centro.

El acanto utilizado en estos capiteles puede plantear, en cierto modo, algún problema - derivado fundamentalmente de su deficiente conservaciónen lo que concierne a su exacta vinculación tanto estilística como cronológica. De hecho, si bien es posible la restitución del capitel a partir de los fragmentos encontrados, no es menos cierto también que su deterioro puede inducir a errores de apreciación. Si se toma únicamente como referencia el fragmento correspondiente a las dos hojitas de perfil que constituyen el cáliz de los caulículos, su vinculación con el tipo de acanto denominado simétrico parece bastante clara en relación al carácter geométrico de los motivos originados - círculo seguido de dos triángulos- en el punto de contacto de las digitaciones. Estos motivos geométricos podrían hacer pensar, incluso, en un tipo concreto de acanto, el denominado «a flèches» por Roth-Conges ${ }^{18}$.

18 A. Roth Conges, «L'acanthe dans le décor architectonique protoaugustéen en Provence», RAN, XVI, 1983, pp. 104- 
Sin embargo, creemos que en este caso, sería mas acertado pensar en una modalidad de acanto mas evolucionada, de corte naturalista, si bien manteniendo ese geometrismo en la realización de los cálices de los caulículos. En este sentido, hay que señalar la existencia de otro capitel cluniense, bastante completo, que combina la presencia de un acanto, en cierto modo naturalista en el kalathos, junto con los motivos geométricos citados en el cáliz de los caulículos ${ }^{19}$. Desde el punto de vista cronológico esta modalidad de acanto se adecua mejor con respecto a la datación que proporcionan el resto de los elementos arquitectónicos del templo que, como ya adelantamos, nos sitúan en época tiberiana.

El acanto simétrico es el que domina en la decoración arquitectónica de un buen número de construcciones tanto de Roma e Italia como de otros ambientes provinciales a partir de los comienzos de la segunda mitad del s. I a.C., para dejar de utilizarse en torno al cambio de era, momento en el que será suplantado de forma definitiva por el denominado acanto disimétrico o naturalista, si bien este último es, en parte, contemporáneo del anterior ${ }^{20}$. De hecho, hay un periodo de tiempo en el que en un mismo edificio se combinan ambas modalidades; así sucede, por ejemplo, en la Puerta de Augusto en Nîmes o en el parascaenium del teatro de Arles ${ }^{21}$.

En cualquier caso, capiteles similares a los clunienses son harto frecuentes en todo el mundo romano; así, los capiteles de la Basílica Emilia o los del templo de los Dioscuros en Roma ${ }^{22}$, los del Arco de Sergio en Pola ${ }^{23}$, algunos de Ostia ${ }^{24}$, o los de la Maison Carrée ${ }^{25}$, Arles ${ }^{26}$ o Saintes ${ }^{27}$. La Península Ibérica ofrece, asimismo, numerosas piezas

106 en las que se describen las distintas modalidades de acanto, con las características específicas de cada una de ellas.

${ }^{19}$ Capitel procedente de la casa $n^{\circ} 1$, hoy en el Museo Numantino de Soria, de menores dimensiones que el que se propone para el templo, pero de rasgos muy similares: M.A. Gutiérrrez Behemerid, «Estudio de los capiteles romanos de la Península Ibérica», Studia Archaeologica, 81, 1992, $\mathrm{n}^{\circ}$ 178.

20 A. Roth Conges, cit. nota 18 , figs. 13 y 37

${ }^{21}$ Ibidem, pp. 106-108 donde se recogen una serie de edificios con esta modalidad de acanto y sus dataciones correspondientes.

${ }^{22}$ W.D., Heilmeyer Korinthische Normalkapitelle. Studien zur Geschichte der römischen Architekturdekoration, RM, Supl. 16, 1970, lám. 44.

${ }^{23}$ G. Fischer, Das römische Pola. Eine archäologische Stadtgeschichte, München, 1996, lám. 10.

${ }_{24}$ P. Pensabene, Scavi di Ostia. VII. I Capitelli, Roma, 1973, núms. 212 a 220.

${ }^{25}$ R. Amy y P. Gros, cit. nota 15, láms. 58 a 65.

26 A. Roth Conges, cit. nota 18, fig. 37.

$27 \mathrm{D}$. Tardy, Le décor architectonique de Saintes Antique, Aquitania Suppl., 5, 1989, fig. 13.
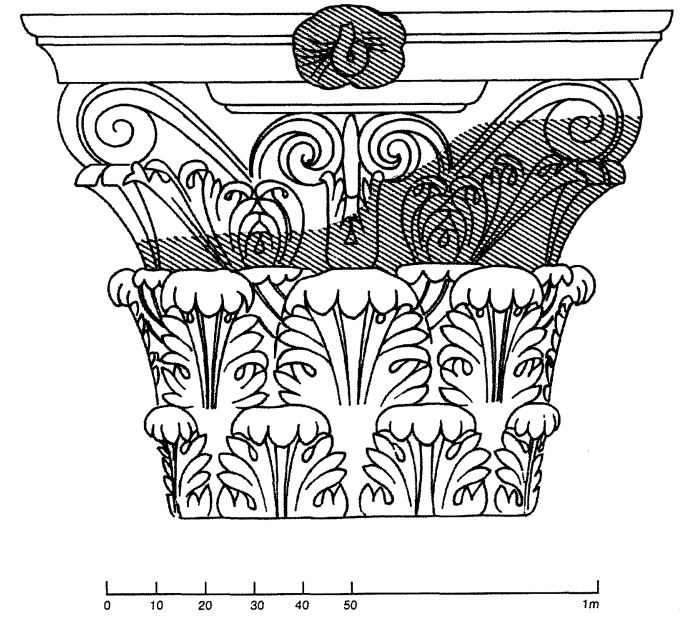

Fig. 2.-Restitución del capitel del templo.

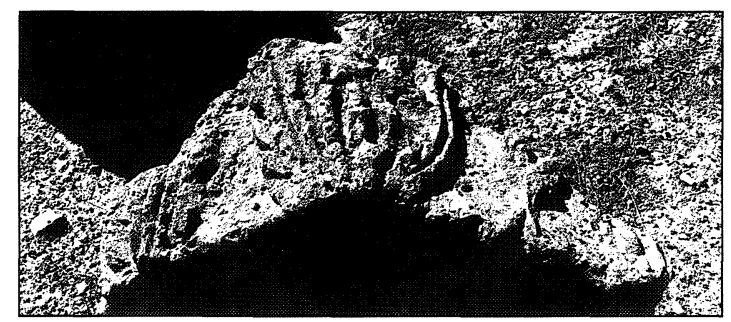

Fig. 3.-Capitel del templo.

análogas cuya datación se sitúa entre las épocas tardoaugustea y la tiberiana ${ }^{28}$.

El sistema que se ha utilizado en la confección del capitel, dos bloques que se unen por encima de la orla de los caulículos, es un rasgo que se manifiesta en época augustea y que presupone el trabajo de canteros poco habituados a los esquemas del capitel corintio.

El análisis detallado de la cornisa será el que nos permita acercarnos mejor a su encuadramiento tipológico y nos proporcione una mayor precisión a la hora de establecer su datación definitiva (fig. 4). La cornisa se presenta tallada en tres bloques independientes: el registro inferior, del que forman parte los dentículos, un bloque central constituido por los casetones y las ménsulas junto con la corona y, finalmente, la sima, moldurada en una kyma recta, que supone el remate final de la cornisa.

La subcornisa está constituida por un talón que serviría, a su vez, de elemento de unión con el friso. No ofrece ningún tipo de ornamentación y se

${ }^{28}$ Entre otros los procedentes de Zaragoza, Pamplona, Ercavica, Valeria...: M.A. Gutiérrez Behemerid, cit. nota 19, núms. 173, 191, 206, 211, 212, 216. 

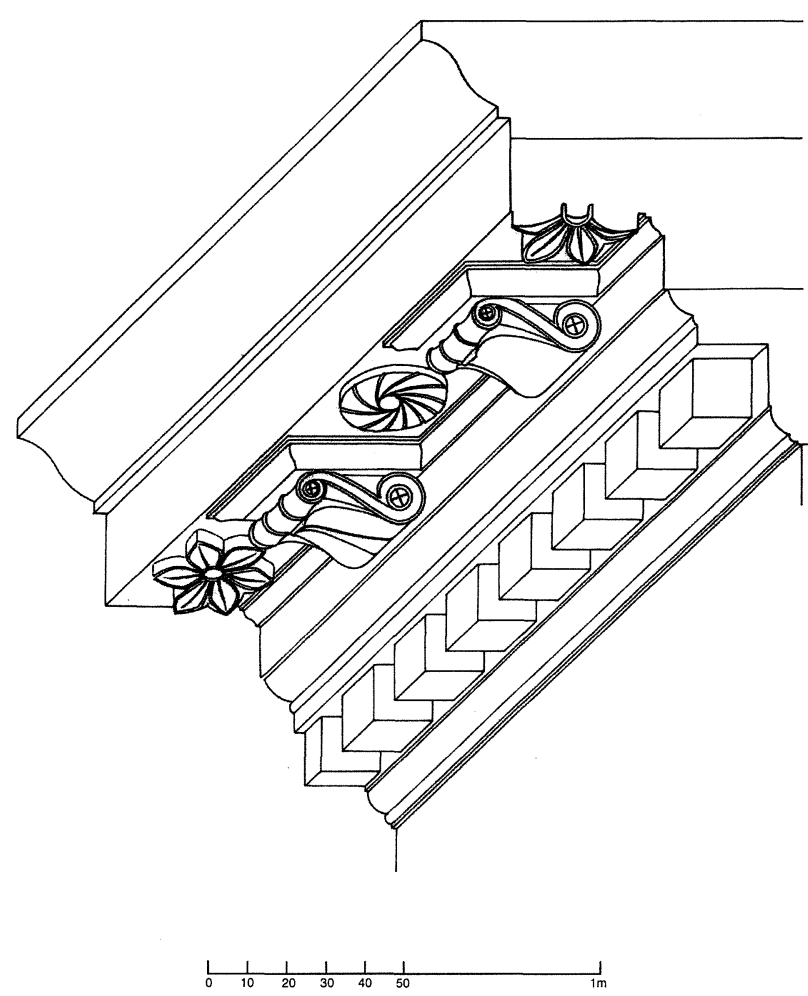

Fig. 4.-Restitución de la cornisa.

sitúa entre dos delgados listeles. Los dentículos (fig. 5) presentan una estructura cuadrangular, casi cúbica, y se sitúan de forma bastante aproximada, separados por profundos y estrechos espacios intermedios, sin ningún elemento de unión entre ellos, equivalentes escasamente a la mitad de su anchura. Estos rasgos que se acaban de señalar son prácticamente los mismos que se documentan en diferentes construcciones datadas en época proto-augustea ${ }^{29} \mathrm{y}$ que se mantendrán durante las tardoaugustea y tiberiana tal y como se puede comprobar en el templo de Mars Ultor ${ }^{30}$, en el de Saturno ${ }^{31}$, en el de la Concordia o en el de Castor ${ }^{32}$ por citar únicamente los ejemplos mas significativos en el ámbito romano. A ellos se pueden añadir los del templo de Roma y Augusto en Pola ${ }^{33}$ o algunos ejemplos galos como la Maison Carrée o Arles ${ }^{34}$. En la mayo-

\footnotetext{
${ }^{29}$ R. Amy y P. Gros, cit. nota 15, p. 161.

30 P. Gros, cit. nota 12, lám. XLVII.

31 Ibidem, lám. XLIII; P. Pensabene, Tempio di Saturno. Architettura e decorazione, Roma, 1984, figs. 33 a 37.

32 F. Toebelmann, Römische Gebälke, Heildelberg, 1923, figs. 44 y 48; GASPARRI, C., Aedes Concordiae Augustae, I Monumenti Romani, Roma, 1979, figs. 69 a 75 y lám. XI,1.

${ }^{33}$ G. Fischer, cit. nota 23 , figs. 5 y 6

${ }_{34}$ P. Gros, «Un programme augustéen: Le centre monumental de la colonie d'Arles», Jd'AI, 102, 1987, figs. 5 y 6.
}

ría de los casos las molduras que acompañan a los dentículos se decoran con diferentes kymatia. Así, la presencia de un cuarto bocel -decorado con un kyma jónico, sobre los dentículos en el paso de la subcornisa a la cornisapuede considerarse como un elemento relativamente canónico, que se documenta, entre otras, en las cornisas del Foro de Augusto o en las del templo de la Concordia. A veces el kyma jónico es sustituido por el tipo lésbico - Templo de Roma y Augusto en Ostia- o bien los dentículos se disponen entre dos kymatia lésbicos diferentes ${ }^{35}$. No es, en absoluto, excepcional el que las molduras comparezcan lisas y así ocurre en varios edificios de época protoaugustea como son el templo del Divo Iulio o el de Saturno ${ }^{36}$. El hecho de que las molduras que acompañan a los dentículos se presenten lisas o decoradas no está en relación, sin embargo, con la utilización de un tipo concreto de ménsula sino que es aplicable a las distintas variantes que se desarrollan a lo largo de la época agustea. Es decir, son diferentes soluciones que hacen referencia a esta fase de experimentación que caracteriza a la arquitectura augustea ${ }^{37}$. La forma de los dentículos clunienses presenta ciertas analogías con los del templo de Mars Ultor ${ }^{38}$ y coincide también con la que Wegner señala para el templo de la Concordia ${ }^{39}$.

La parte central de la cornisa se decora con ménsulas y casetones alternando. Las ménsulas (figs. 6 y 7) ofrecen un perfil en forma de $S$ horizontal, con doble voluta, la posterior bastante más desarrollada, rematándose en un pequeño balteo en el frente apoyado sobre la parte superior de la hoja. Los lados están perfilados por un canal cóncavo, con los márgenes en resalte que, siguiendo el contorno de la ménsula, dibuja las volutas. El centro de cada voluta se decora con un sencillo motivo en aspa. La parte inferior de la ménsula muestra una hoja lisa que, en algunos casos, presenta nervadura central por lo que se combinarían las dos variantes.

Esta modalidad de ménsula se inscribe dentro de los tipos que se desarrollan fundamentalmente durante las épocas tardoaugustea y tiberiana, siendo el final de una evolución que puede seguirse a través de diferentes ejemplos en el ámbito romano. Se tra-

\footnotetext{
35 P. Pensabene, cit. nota 12, pp. 133-135.

${ }^{36}$ P. Gros, cit. nota 12,lám. XLII, 2 y 3; M. Montagna, cit. nota 14 , p. 279.

${ }^{37}$ P. Pensabene, cit. nota 12 , pp. 133-135.

38 M. Montagna, cit. nota 14 , lám. LXII, 2 y 3.

${ }_{39} \mathrm{M}$. Wegner, Ornamente Kaiserzeitlicher Bauten Roms,
} Köln, 1957, p. 50. 
ta de un tipo de ménsula que comenzaría su desarrollo en los primeros momentos de la época augustea presentando una débil curvatura posterior y el frente recto, tal y como puede verse en el templo de Saturno o en la Regia, para ir adoptando un ligero engrosamiento central - templo de Mars Ultor-, hasta adquirir su forma definitiva, con doble voluta de diferente desarrollo, en el templo de Castor y en el de la Concordia, desplazando a los otros tipos e imponiéndose esta modalidad en épocas sucesivas ${ }^{40}$. El perfil que ofrecen las ménsulas del templo cluniense permite una clara vinculación estilística con las documentadas en el templo de la Concordia; en nuestro caso, una vez más, con una forma más sencilla, sin ningún tipo de ornamentación. Vemos, por ejemplo, como las rosetas que ocupan las volutas en las ménsulas del templo de la Concordia se limitan aquí a sendas aspas.

Las ménsulas se separan por espacios prácticamente cuadrados, sin que puedan considerase como auténticos casetones ya que no se presentan delimitados en sus cuatro lados (figs. 8 y 9). El enmarque del casetón se efectúa mediante una moldura lisa, en forma de gola invertida, que se desarrolla en torno a las ménsulas y el fondo, dejando libre el frente. Estos espacios cuadrados están ocupados, al menos, con dos tipos de flor a juzgar por los fragmentos encontrados. Se trata, en un caso, de una flor formada por una corola de seis grandes pétalos lanceolados, ligeramente apuntados, que se disponen en torno a un botón central, siguiendo las diagonales del casetón. Tanto el margen externo como la nervadura se delimitan mediante una profunda incisión. Las rosetas son motivos decorativos frecuentes en los casetones de las cornisas augusteas y julio-claudias; con una o dos corolas de pétalos, siguiendo siempre las diagonales del casetón, a partir de los modelos establecidos en el Foro de Augus-

40 I. Soderstrom, «Studi sulla mensola romana dal periodo della tarda repubblica fino all'epoca flavia», Opuscula Archaeologica, V, 1948, pp. 146-155.

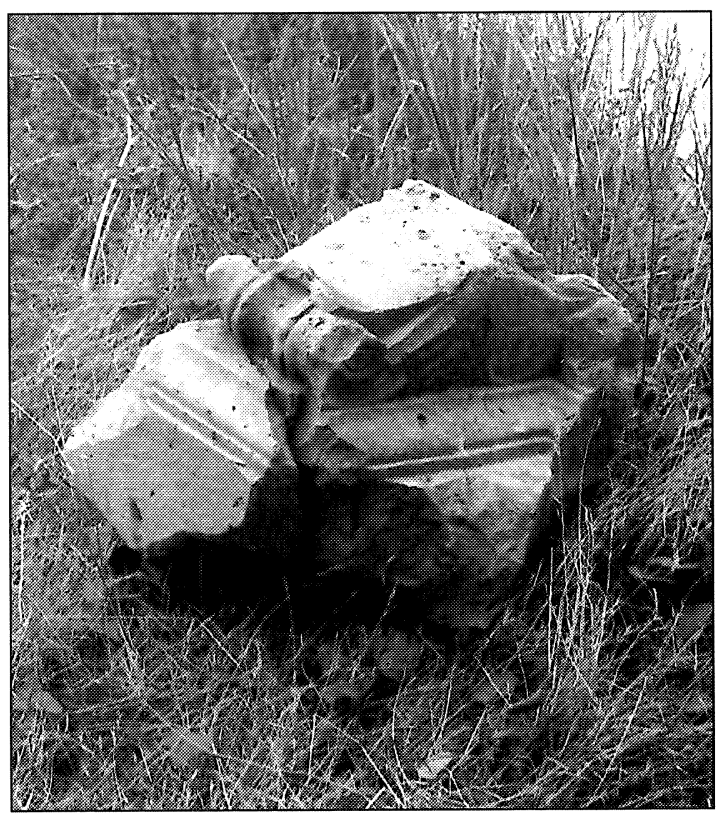

Fig. 7.-Registro medio de la cornisa: ménsula de hoja lisa. 


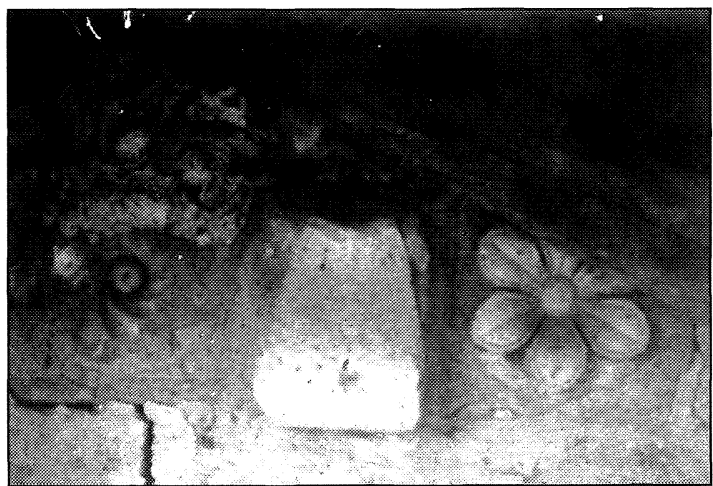

Fig. 8.-Registro medio de la cornisa: casetones y ménsulas.

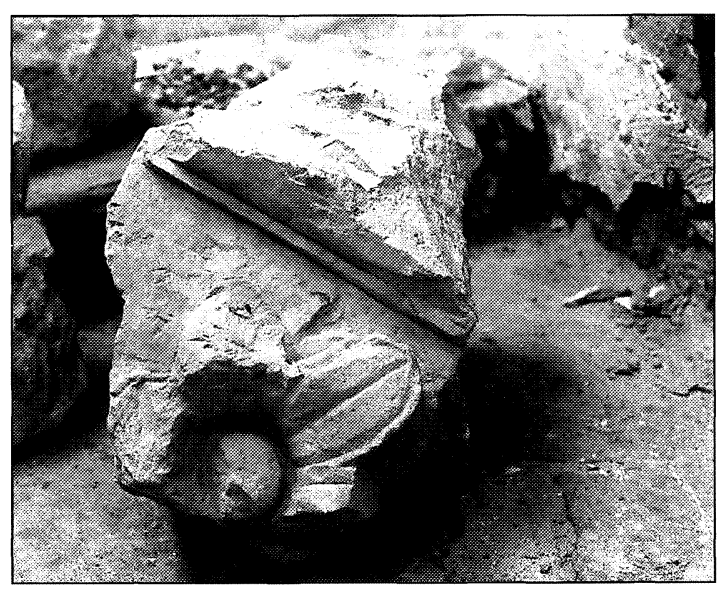

Fig. 9.-Registro medio del la cornisa: casetón.

to ${ }^{41}$. La segunda modalidad consiste en una girándola, de factura poce naturalista. La girándola, por su parte, se inserta dentro de los tipos derivados de la tradición tardorrepublicana con una gran popularidad en épocas posteriores. Son, por lo tanto, numerosos los ejemplos análogos a los clunienses ${ }^{42}$.

El remate final de la cornisa, con la corona lisa y la sima perfilada en una kyma recta, sin elementos decorativos, es otro rasgo que manifiestan las cornisas de época augustea ${ }^{43}$.

Por lo que se refiere a la acrótera (figs. 10 y 11), sus dimensiones hacen pensar en su pertenencia a

${ }^{41}$ P. Pensabene, cit. nota 12, pp. 135 y 136.

42 Rosetas y girándolas similares en el templo de Saturno: P. Pensabene, cit. nota 31, núms. 14, 19 y 20. En Glanum: rosetas y girándolas además de ménsulas de hoja lisa con nervadura central, alternando con ménsulas de acanto; molduras que enmarcan los dentículos lisas: P. Gros, cit. nota 12 , figs.12, 13, 31 y 33; en Córdoba: ménsulas de hojas lisas con nervadura central: núms. 26,131 y 746 y rosetas análogas: núms. 70, 20 y 58: C. Márquez, La decoración arquitectónica de Colonia Patricia. Una aproximación a la arquitectura y al urbanismo de la Córdoba romana, Córdoba, 1988.

${ }_{43}$ R. Amy y P. Gros, cit. nota 15, pp. 165-166. un edificio templar mas que, por ejemplo, en el remate de un monumento funerario. Se trataría, en suma, de la decoración de uno de los vértices del frontón. La pieza mayor corresponde a una acrótera angular, que adopta la forma de una semipalmeta. Se apoya sobre una base lisa, con un elemento central, triangular y liso, a partir del cual se desarrollan largos lóbulos rematados en espiral. Los otros dos fragmentos corresponden a remates de sendas espirales. Ejemplos similares son abundantes tanto en la Galia ${ }^{44}$ como en el norte de Italia ${ }^{45}$.

$\mathrm{Si}$ bien es relativamente fácil encontrar en el mundo itálico ejemplos de cornisas que puedan paralelizarse con las clunienses, no sucede lo mismo dentro del ámbito hispano, ya que son escasos los perfiles completos conocidos de cornisas que se sitúen cronológicamente entre la época medio, tardoaugustea y los comienzos de la imperial. Los ejemplos más próximos - templo de Barcelona o de Diana en Mérida - apenas sirven en este sentido. Únicamente el templo de Barcelona muestra algunos motivos decorativos - girándolas- que guardan un cierto parentesco con las clunienses, si bien teniendo en cuenta que estas últimas son posteriores. Sin embargo, en lo que se refiere a la configuración general del perfil de la cornisa - modalidad de ménsula - se sitúa en un estadio anterior, menos evolucionado que el cluniense. En este sentido, podría citarse la cornisa del teatro de Tarragona, aunque la forma de las ménsulas y la realización de los motivos florales de los casetones correspondería a un momento anterior ${ }^{46}$. Lo mismo cabe señalarse con respecto a un fragmento de cornisa procedente de Carteia, cuyo tipo de ménsula se situaría entre la del templo de Barcelona y la de Clunia ${ }^{47}$. Mayor aproximación tipológica presentan varios fragmentos procedentes de Córdoba, si bien realizados en mármol y de menores dimensiones, que se fechan entre la época tardoaugustea y la tiberiana ${ }^{48}$.

Como hemos tenido ocasión de comprobar, el modelo para la cornisa del templo cluniense se encuentra, pues, en la arquitectura tardoaugustea fun-

${ }^{44}$ G. Ch. Picard, «Glanum et les origines de l'art romanoprovençal», Gallia, 22, 1964, p. 124, fig. 9.

${ }_{45}$ G. Cavalieri Manase, La decorazione architettonica di Aquileia, Trieste, Pola. L'etá Repubblicana, Augustea e Giulioclaudia, Padova, 1978, láms. 34 y 35.

${ }^{46} \mathrm{P}$. Pensabene, «Classi sociali e programmi decorativi nelle province occidentali», Actas XIV Congreso Internacional de Arqueología Clásica, Tarragona 1993, Tarragona, 1994 , p. 315 y fig. 30.

${ }^{47} \mathrm{H}$. Von Hesberg, «Bauornamentik als kulturelle Leitform», Stadtbild und Ideologie. Die Monumentalisierung hispanischer Städte zwischen Republik und Kaiserzeit, Kolloquium Madrid, 1990, München, 1992, lám. 33.

${ }^{48}$ C. Márquez, cit. nota 42, lám. 30, nº 73 . 
damentalmente, a partir de las directrices que emanan de las grandes construcciones romanas de este momento. Creemos que es evidente su relación con el templo de la Concordia al que habría que añadir también el templo de Castor en el foro romano ${ }^{49} \mathrm{o}$ el templo de Roma y Augusto en Pola ${ }^{50}$. La cornisa proporciona, además, el momento final de la construcción del templo puesto que es el elemento más evolucionado de todo el
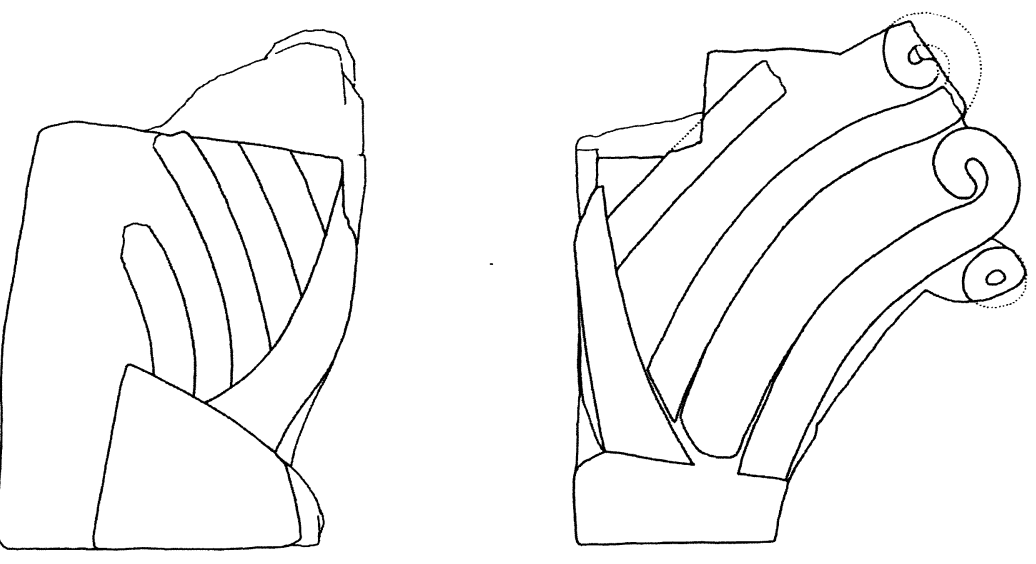
conjunto.

Del estudio de los diferentes elementos del templo, tanto tipológicos como decorativos, se deduce un marco cronológico global que comprendería desde la época augustea a los primeros momentos de la tiberiana. En este caso concreto, creemos que los comienzos de la época tiberiana podría ser la adecuada para considerar el momento de la construcción del templo de Júpiter. Esta datación concuerda, a su vez, con otros materiales que

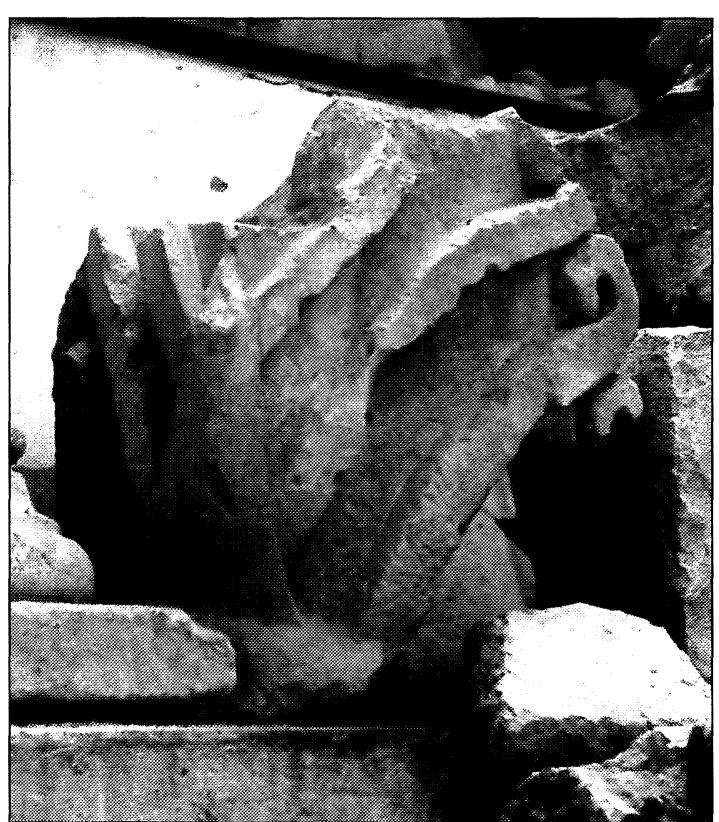

Fig. 11.-Acrótera.

${ }^{49}$ D.E. Strong, «Some observations on Early Roman Corinthian», JRS, LIII, 1963, lám. VIII, 5.

${ }^{50}$ G. Fischer, cit. nota 23, p. 86, lám. 22.

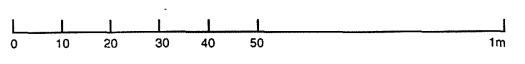

Fig. 10.-Restitución de la acrótera.

ha proporcionado la ciudad y que viene a corroborar una importante actividad edilicia ya desde estos momentos iniciales. El templo cluniense sería, en definitiva, una buena muestra de la recepción de los modelos oficiales, urbanos, y de su interpretación en un ambiente provincial.

\section{PROPUESTA DE RESTITUCIÓN}

Actualmente, gracias a la presencia de la moldura inferior del podio, es fácil leer a grandes rasgos la planta del edificio a pesar de que los puntos de unión de los muros no se acabaron de completar en el momento de la restauración, posiblemente por un prurito de rigor. La planta que se dibujó del templo en aquel momento sugería la posición de los ángulos con línea discontinua, un dato constructivo que todavía se aprecia con bastante nitidez en el relleno de caementicium. A partir de aquí, y de nuevas mediciones, se obtiene una silueta del podio con unas dimensiones y proporciones (fig. 12) similares a las de otros templos coetáneos de gran tamaño. Nada más se puede asegurar respecto a la distribución de volúmenes, tan sólo planteada en la figura como elemento de comprensión. No es posible, por ejemplo, establecer la profundidad de la pronaos y de la cella, si bien las dimensiones del podio sugieren una proporción de 1:2 entre el ancho y la profundidad del edificio.

Lo que no ofrece ninguna duda en cuanto a su pertenencia al proyecto original es la peculiaridad tipológica de presentar un podio absidado. Si la apa- 


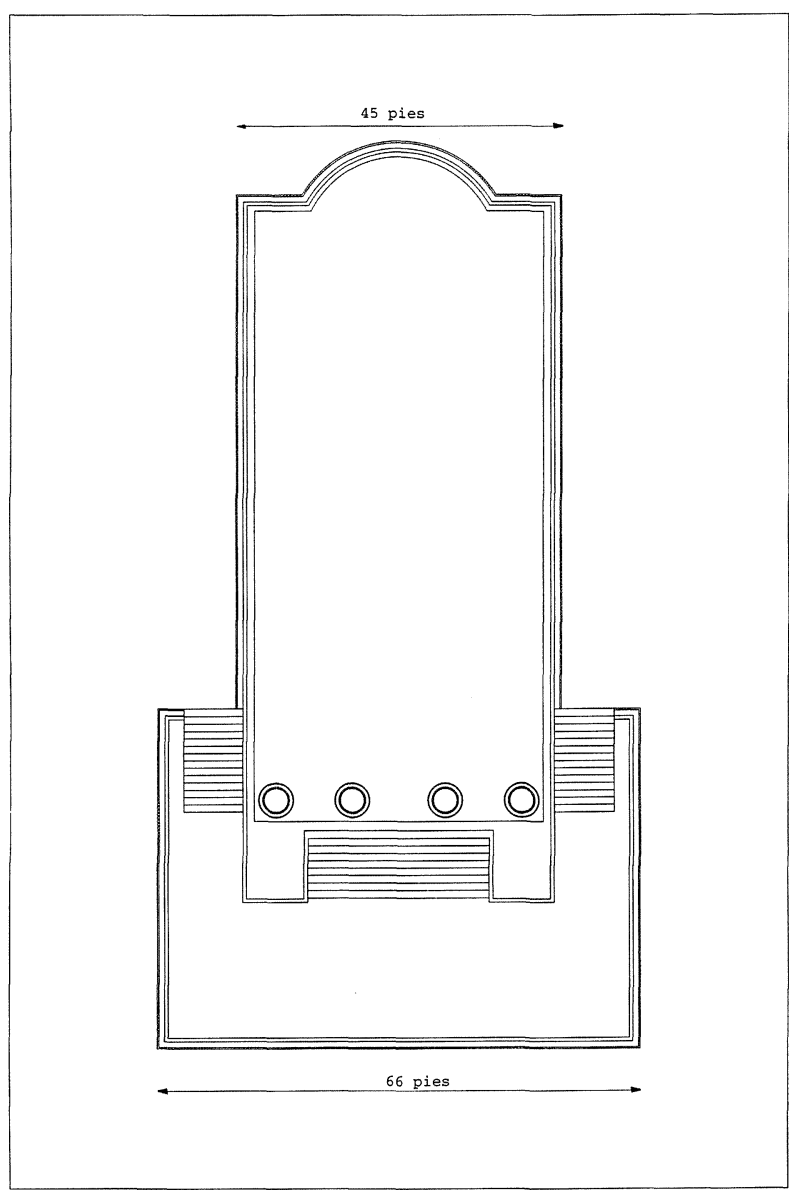

Fig. 12.-Aproximación a los volúmenes del podio.

rición de ábsides al fondo de la cella, situados en posición axial, tal y como aparece en el templo de Venus Genitrix o en el de Mars Ultor -entre otros-, se remonta a la época cesariana, hay que hacer notar, sin embargo, que en los citados casos la curvatura no se refleja en la fachada, como sucede en el ejemplo cluniense, sino que se trata de templos sine posticum. Sólo con la reorganización religiosa de Augusto, se dan templos con ábside marcado, la mayor parte de las veces relacionados con el concepto de Fortuna ${ }^{51}$. Y en estos casos, el ábside sólo remata la cella pero no el podio. Su presencia en el templo de Clunia representa un caso aparentemente anómalo en un panorama tipológico que, sin embargo, tampoco permite hablar de ortodoxia. Por eso, la concreta atribución religiosa del templo, tal como subrayábamos al principio, se deberá avanzar, en otra sede, a partir de un razonamiento más global que supere los enfoques tipológicos más rí-

51 P. Gros, cit. nota 12, pp. 124-143. gidos. El ábside, la presencia de una plataforma intermedia, el acceso posterior a la fachada, son tres datos a conjugar no sólo para entender las características del culto, sino de la propia configuración de la plaza foral ${ }^{52}$.

En cuanto a la restitución de los elementos del alzado del templo, lo que se ha valorado fundamentalmente es la disposición y el número de columnas de la fachada, al poner en relación el diámetro con la anchura del podio. Además, se han valorado las dimensiones de los elementos arquitectónicos para comprobar su adecuación a las relaciones proporcionales usuales y para proponer una restitución gráfica cuya finalidad principal es ofrecer una imagen expresiva del aspecto del templo en su concepción original. Los datos obtenidos conjugando la teoría y la realidad arqueológica han permitido descartar una configuración hexástila y pseudoperíptera que daría como resultado una fachada excesivamente comprimida. Se propone, pues, una fachada próstila y tetrástila con un ritmo éustilo para la columnata. Veamos el porqué.

Para comenzar, como veíamos, el podio no consiste en una estructura rectangular simple sino que presenta un ábside posterior. La valoración de las dimensiones y del ritmo de las columnas, que veremos a continuación, obliga a descartar una solución pseudoperíptera ya que las pilastras o semicolumnas adosadas, con dimensiones necesariamente proporcionadas a las de la fachada, no podrían completar su recorrido por la parte posterior, es decir, en el perímetro del ábside. Esta razón lleva a pensar que el templo se entiende mejor como simplemente próstilo.

Para trabajar con la anchura de la pronaos, se ha tenido que partir de las dimensiones del podio a ras del suelo de la plaza e ir deduciendo, por sustracción de las medidas superfluas, cuál podía ser la superficie útil para el asiento del templo unos metros más arriba. La dimensión más precisa de la que partir la aportan los extremos de la plataforma porque tras varias mediciones se ha comprobado que el resto del podio presenta una ligera deformación. El ancho de la primera plataforma, con $19,60 \mathrm{~m}$ en total, alcanza los $18,65 \mathrm{~m}$ sin las molduras y retranqueos de cada lado, mientras que el ancho de la segunda plataforma arroja una dimensión de 12,42 m, descontando igualmente las molduras respectivas ${ }^{53}$.

${ }^{52}$ Uno de estos rasgos -escaleras de acceso lateral- se documenta en varios templos de Lusitania: Mérida, Evora, Miróbriga, Egitania, fechados en los comienzos de la época imperial: Hauschild, T., en: Hispania Antiqua. Denkmäler der Römerzeit, Mainz am Rhein, 1993, p. 277. 
Señalemos, de inmediato, que esto prácticamente equivale en el primer caso a 63 pies romanos de $0,296 \mathrm{~m}(18,648 \mathrm{~m})$ y en el segundo a $42 \mathrm{p}(12,432$ $\mathrm{m})$. El límite de esta última superficie suele coincidir (aunque también es frecuente la presencia de un peldaño adicional) con el canto del plinto de la columna o, en su defecto, con la tangente de la basa. De modo que la cella tendría que encajar en un rectángulo de $42 \mathrm{p}$ de ancho como máximo.

Por otra parte, la traducción a pies romanos de los $0,97 \mathrm{~cm}$ de diámetro del fuste arrojan como cifra más ajustada la de $31 / 4 \mathrm{p}(0,962 \mathrm{~cm})$. Lo cierto es que dicha medida podía ser incluso superior puesto que los fustes de los edificios religiosos de este momento acostumbraban a ser acanalados, lo que en este caso se conseguiría con un acabado de estuco. De modo que no tenemos la seguridad de que ésta fuera la cifra precisa que serviría para proporcionar el orden completo. Además, quedaría pendiente una discusión todavía más sutil acerca del punto de medición del diámetro de la columna ${ }^{54}$. Aunque esta dimensión aparezca en las dos citadas piezas, lo que sugiere que es significativa, hemos de considerar la posibilidad de que el diámetro final de la columna fuera mayor. Si además observamos que los $42 \mathrm{p}$ de ancho del podio son un múltiplo exacto de un módulo de $31 / 2$ p podemos avanzar la hipótesis de que el diámetro final de la columna estucada se ciñera a dicha cifra en pies romanos. Se trataría de la división del podio entre 12 partes iguales, algo adecuado al sistema de medidas romano y que proporciona un método simple de replanteo. Nos encontramos pues ante una cuestión importante: $¿$ a partir de cuál de las dos medidas posibles se habrá proporcionado el orden del templo? ¿A partir del diámetro sin el acabado de estuco o a partir de la dimensión final?

Lo cierto es que no se puede trabajar directamente a partir de los $42 \mathrm{p}$ del podio puesto que los sistemas de distribución de las columnas, tal como

${ }^{53}$ La plataforma de cimentación mide en este punto 13,30 $\mathrm{m}$ de ancho. Sin embargo el plano vertical del podio, descontando el ancho de la moldura inferior y el ligero desplazamiento respecto al borde de la plataforma, se sitúa $0,44 \mathrm{~m}$ más adentro por cada lado. Por lo tanto la dimensión correcta del ancho del podio es de $12,42 \mathrm{~m}(13,30 \mathrm{~m}-0,44 \mathrm{~m} \times 2)$.

54 No podemos precisar la medición de la columna a la altura de la apófige o antes del inicio de la éntasis porque nos falta el acabado de la pieza. Es preciso reconocer que esta disyuntiva sobre la medida que se usa como módulo en la discusión sobre la distribución de columnas, plantea dudas en la restitución de otros templos. Véase para esta discusión el comentario de P. Gros en Vitruve. De l'architecture Livre III, Les Belles Lettres, París, 1990, p. 203. De todas formas, pensamos que en una columna con un núcleo duro y revocado de estuco, lo más probable es que el dimensionado de la columna no presente las sutilezas de las columnas de mármol. los conocemos a través de Vitruvio (III,3,2), juegan con el concepto de intercolumnio, la distancia entre las caras exteriores de las columnas de los extremos. Por lo tanto, para obtener el intercolumnio global habrá que restarle al ancho del podio, por lo menos lo que ocupe la parte de la basa que excede al diámetro de la columna. Para conocer las dimensiones de una basa sin plinto, de perfil ático, como las de la basílica de Clunia, podemos acudir a Vitruvio (III,5,1) quien señala que el ancho de la basa valdrá un diámetro y medio de columna: $51 \frac{1}{4} \mathrm{p}$ $(1,554 \mathrm{~m})$ para una columna de $31 / 2 \mathrm{p}$ y una cifra inferior a $5 \mathrm{p}(1,443 \mathrm{~m})$ en el caso de una columna de $31 / 4 \mathrm{p}$. Así, a los $42 \mathrm{~m}$ de ancho del podio habría que restarle $1 / 2$ diámetro de basa, puesto que a lado y lado habría una diferencia $1 / 4$ de diámetro desde la vertical de la cara externa de la columna hasta la de la tangente de la basa. Si optáramos por una columna con plinto, podríamos acudir a estudios modernos y restituir otra serie de medidas ${ }^{55}$. Nuestro interés en determinar esta medida radicaría en poder restar, a cada lado de la plataforma, la distancia que separa la tangente del fuste de la tangente de la basa, para así poder operar con la dimensión de un intercolumnio global. Así, en el caso de una basa ática, a los $42 \mathrm{~m}$ de ancho del podio habría que restarle $1 / 2$ diámetro de la basa, puesto que a lado y lado habría una diferencia $1 / 4$ de diámetro desde la vertical de la cara externa de la columna hasta la de la tangente de la basa. Pero al plantear dos disyuntivas sucesivas en torno al diámetro y a la basa, las opciones aquí se nos multiplican, de modo que pensamos que sería más operativo retomar el estudio de la dimensión del podio como múltiplo de un módulo de $31 / 2 \mathrm{p}$. Y empezar por eliminar opciones por lo que se refiere al número de columnas.

Para empezar, la hipótesis de una configuración hexástila queda inmediatamente descartada porque, en el mejor de los casos, con una columna de $31 / 4 \mathrm{p}$, en el podio sólo habría espacio para una separación entre columnas equivalente a un diámetro y cuarto, es decir, una separación menor que la que Vitruvio estipula para el ritmo picnóstilo, el más prieto, equivalente a un diámetro y medio de columna ${ }^{56}$. En

${ }^{55}$ Según Wilson Jones, aunque en teoría la diagonal del plinto es el doble - o casi- del diámetro inferior de la columna (lo que equivaldría a multiplicar el diámetro por la raíz de 2 para obtener el lado), en la práctica, el lado del plinto a menudo está más cerca de la relación 7:5. Por lo tanto, nuestro plinto mediría cerca de $5 \mathrm{p}$ en el caso de una columna de $3 \frac{1 / 2}{\mathrm{p}}$ o bien alrededor de $4 \frac{1}{2} \mathrm{p}$ con el diámetro más reducido. M. Wilson Jones, «Designing the Roman Corintian Order», Journal of Roman Archaeology, 3, 1989, pág. 47.

56 Acerca del ritmo de disposición de las columnas en una fachada de orden jónico, véase Vitruvio III, 3,2. Es cierto 


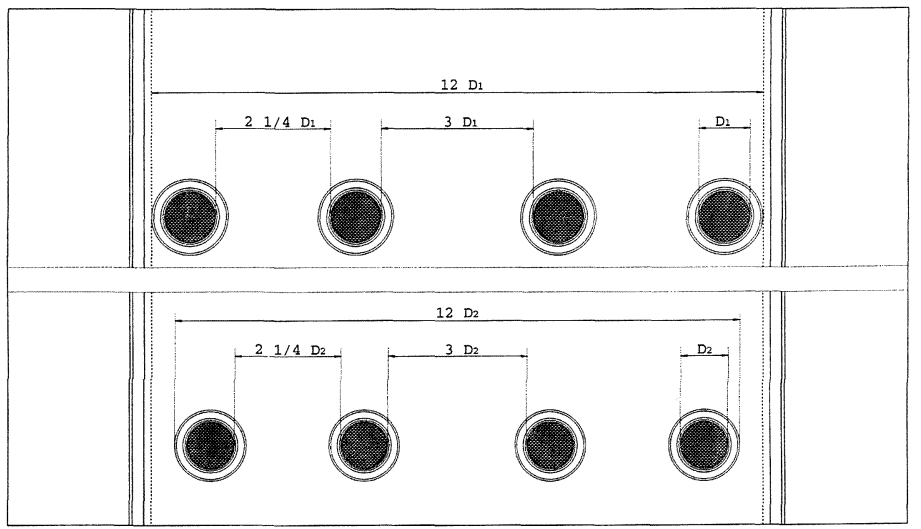

Fig. 13.-Disposición de las columnas según el ritmo éustilo para D1=31/2 pies y para $\mathrm{D} 2=3^{1 / 4}$ pies.

cambio, en una distribución tetrástila el ritmo de la columnata se situaría entre los llamados sístilo y diástilo. Descartados tanto el ritmo diástilo, puesto que no tiene cabida en el ancho del podio, como el sístilo, ya que no lo ocuparía del todo, nos queda otra posibilidad dentro de las normas: el ritmo éustilo. Vitruvio refiere que en dicho ritmo se da un espaciamiento mayor en las columnas centrales lo que deja la suma de módulos como sigue: 4D + 2 (2 1/4

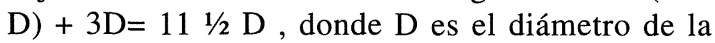
columna ${ }^{57}$. Vale la pena notar que esta distribución se ajusta perfectamente a un podio de $42 \mathrm{p}$ de ancho que soportara cuatro columnas de $31 / 2 \mathrm{p}$ con basas sin plinto, puesto que añadiendo el espacio sobresaliente de las basas en los dos lados ( $1 / 2 \mathrm{D})$, se obtiene una distribución de la longitud en 12 partes iguales, sistema que hemos visto operativo para el templo de Clunia.

Si quisiéramos verificar el funcionamiento de esta disposición para el caso de un fuste de $31 / 4 \mathrm{p}$ de diámetro, sin plinto, no estaríamos ante la situación descrita ya que el espaciamiento sería bastante más complicado y sobrarían $3 \mathrm{p}$ en total ${ }^{58}$. En caso de querer seguir fieles a estos datos, deberíamos imaginar que la tangente de la basa, o el lado del plinto en su caso, no quedaban perfectamente ali-

que los ritmos que transmite Vitruvio no siempre fueron respetados y que muchos de los templos de la ciudad de Roma se ciñen sólo aproximadamente a ese ritmo (por ejemplo Venus Genitrix, Divo Iulio, Apolo Sosianus, Castor y Pollux) pero no conocemos ningún caso en que el intercolumnio sea tan netamente inferior a 1 1/2 diámetros. La Maison Carrée de Nîmes presenta un intercolumnio que se encuentra entre el ritmo picnóstilo y el sístilo. R. Amy y P. Gros, cit. nota 15, p. 105.

57 P. Gros, cit. nota 54, p. 109.

$584\left(3^{1 / 4}\right)+2\left(2^{1 / 4} \times 3^{1 / 4}\right)+3\left(3^{1 / 4}\right)=11^{1 / 2}\left(3^{1 / 4}\right)=37^{3 / 8}$ a lo cual se añadiría $1 / 2(31 / 4)$ de proyección de la basa. En total 39 p de estilobato necesario. neados con la vertical del podio útil, sino algo desplazada, a cada lado, hacia el interior. Numerosos templos presentan este nuevo escalón por encima de la cota final de la moldura superior del podio que es el que ejercería de verdadero estilobato. Una solución que lejos de ser descabellada, proporcionaría al edificio un aspecto más elegante. Por lo tanto aunque la modulación basada en $31 / 2$ sea más simple, el resultado también es más torpe (fig. 13).

Esta disyuntiva acerca del diámetro no es ociosa sino que condicionará también el razonamiento que nos permitirá proponer la restitución en alzado de la columna y de la fachada completa. En efecto, la altura de la columna está relacionada con su diámetro y con el ritmo de su disposición. A partir de la teoría vitruviana, sabemos que en el ritmo éustilo, la columna vale $101 / 6$ su diámetro inferior ${ }^{59}$. Pero sabemos también que la teoría no se verifica casi nunca literalmente ${ }^{60}$. De hecho, las mediciones que Wilson Jones ha efectuado sobre numerosos templos corintios, pone de manifiesto, como criterio muy extendido a partir de la época de Augusto, lo que él llama la norma del 6:5, un sistema de proporción entre la altura de la columna y la del fuste que según el autor no es compatible con la teoría vitruviana. Así, la relación entre diámetro y columna oscila entre el 1:10 y 1:8 en función de otros criterios difíciles de precisar, entre los cuales no puede ser despreciable el problema de la medición del diámetro inferior ${ }^{61}$.

Así las cosas, debemos abandonar el terreno de una restitución que carece de suficientes elementos arqueológicos y seguir adelante con la construcción de un alzado, ya no hipotético, sino simplemente expresivo. Para lo cual, hemos trabajado con las dos series de cifras para ver cuáles confluyen en un dibujo con mediciones más coherentes. El objeto de este ejercicio no es tan sólo didáctico: se trata de comprobar grosso modo si la atribución de los fragmentos encontrados queda avalada por medio de su

59 Según Vitruvio (III,3,10), cada ritmo conllevaría una proporción definida entre la altura de la columna y su diámetro inferior. Así por ejemplo, en el orden jónico, el ritmo picnóstilo exigiría una proporción de 10:1 y el éustilo 9,5:1. Pero en el caso corintio, y puesto que el capitel medirá en altura lo mismo que el diámetro inferior, la altura de la columna en el ritmo picnóstilo sería de 10 2/3 de módulo, y en el éustilo de 10 1/6. Véase P. Gros, cit. nota 54, pp.118-119.

${ }^{60}$ Véase el comentario de L. Frey, «Médiétés et aproximations chez Vitruve» Rev.Arch. 2, 1990.

${ }_{61}$ M. Wilson Jones, cit. nota 55, p. 61; P. Gros, cit. nota 54 , p. 119. 


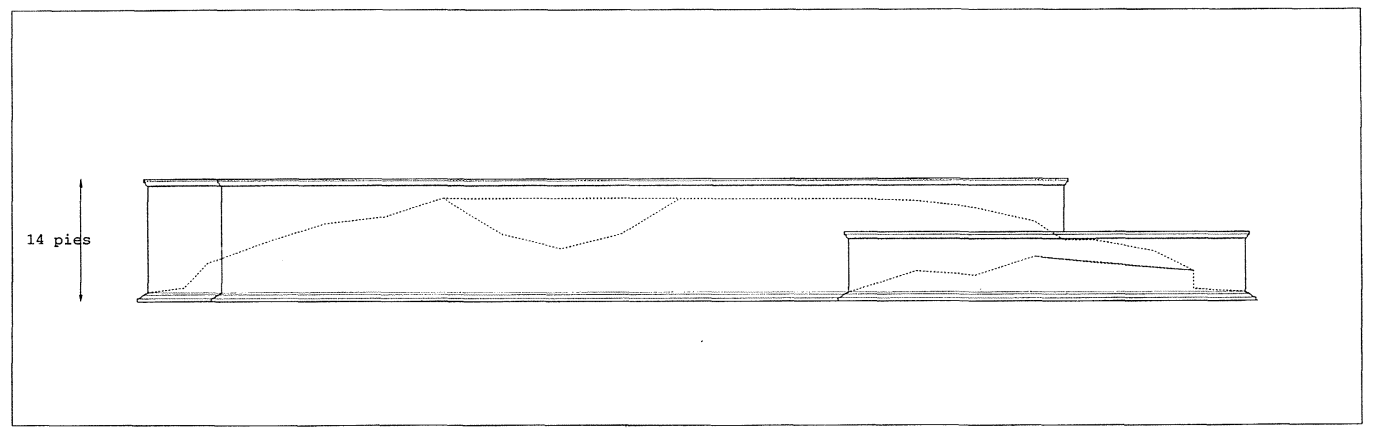

Fig. 14.-Perfil y restitución de la altura del podio.

\begin{tabular}{|l|l|c|l|c|}
\hline Diámetro columna & $\mathbf{3}^{1 / 2} \mathbf{p}$ & $1,036 \mathrm{~m}$ & $\mathbf{3} 1 / \mathbf{4} \mathbf{~}$ & $0,962 \mathrm{~m}$ \\
Podio sin molduras & $\mathbf{4 2}$ & 12,432 & $\mathbf{4 2}$ & 12,432 \\
Estilobato necesario & $\mathbf{4 2}$ & 12,432 & $\mathbf{3 9}$ & 11,544 \\
Intercolumnio global & $\mathbf{4 0} 1 / 4$ & 11,914 & $\mathbf{3 7} 3 / \mathbf{8}$ & 11,063 \\
Altura columna C, 1:10 & $\mathbf{3 5}$ & 10,360 & $\mathbf{3 2}^{1 / 2}$ & 9,62 \\
Entablamento C:4 & $\mathbf{8 3} / 4$ & 2,59 & $\mathbf{8}^{1 / 8}$ & 2,398 \\
Frontón & $\mathbf{9}$ aprox. & $\pm 2,66$ & $\mathbf{8 1}^{1 / 2}$ aprox. & $\pm 2,51$ \\
Total C+E+F & $\mathbf{5 2 3}$ aprox. & $\pm 15,60$ & $\mathbf{4 9}^{1 / 8}$ aprox. & $\pm 14,54$ \\
Podio & $\mathbf{1 4}$ & 4,144 & $\mathbf{1 4}^{14}$ & 4,144 \\
Total del edificio & $\mathbf{6 6}^{3 / 4}$ aprox. & $\pm 19,74$ & $\mathbf{6 3}^{1 / 8}$ aprox. & $\pm 18,68$ \\
\hline
\end{tabular}

Tabla 1.-Recapitulación de dos series de medidas posibles, en la hipótesis de un templo tetrástilo éustilo.

adecuación en cuanto a medidas. En concreto, verificar si los fragmentos de capitel y de cornisa, cuya valoración estilística se desarrolla en otro apartado de este artículo, también apuntan a su pertenencia al templo, analizados desde el criterio dimensional.

Por ejemplo, el fragmento mayor de capitel, que corresponde a algo menos de la altura total del segundo registro, presenta una altura de $45 \mathrm{~cm}$ lo que proporciona una dimensión total que oscila entre los 95 y los $100 \mathrm{~cm}$, lo que viene a coincidir con las del diámetro de la columna en cualquiera de las dos opciones ( $3 \frac{1 / 2}{2}$ o $\left.3 \frac{1}{1 / 4} \mathrm{p}\right)$. Por otra parte, la altura de la cornisa alcanza unos $74,5 \mathrm{~cm}$. La proporción entre arquitrabe-friso-cornisa es variable, si bien la altura del entablamento en su conjunto viene a equivaler aproximadamente a la cuarta parte de la altura total de la columna ${ }^{62}$. Teniendo en cuenta estos datos se ha podido deducir que la altura total del entablamento estaría comprendida entre los 2,40 y los 2,60 m.

El cálculo del frontón, para el que no hay recetas documentadas en las fuentes, arroja entre los $2,50 \mathrm{~m}$ y $\operatorname{los} 2,70 \mathrm{~m}^{63}$. A veces, la acrótera propor.

62 Ibidem, p. 48.

${ }^{63}$ La cifra propuesta se deduce a partir de un cálculo más complejo. Se trata de una aproximación a la cual llegaremos ciona también un indicio de la altura del frontón ya que suele ser equivalente a la mitad del mismo. El fragmento hallado mide, incompleto, cerca de 1,20 $\mathrm{m}$, pero el elemento original alcanzaría sin problemas $1,40 \mathrm{~m}$ lo que aboga por la dimensión más grande del templo.

Si recapitulamos la propuesta comparando la teoría de las proporciones con los elementos arqueológicos constatados, veremos que tanto el entablamento como el frontón restituidos a partir de fragmentos se encuentran en la franja de dimensiones correctas.

Pero el templo no termina con la cella y la pronaos sino que cuenta con una plataforma intermedia respecto a la cual se adoptará el mismo método gráfico y numérico de aproximación al alzado. Al dibujar la sección longitudinal del macizo del caementicium en su estado actual, se apreció con claridad el punto de inflexión entre dos niveles que podían es-

de forma gráfica a partir del dato que proporciona un fragmento de sima y a partir de la suma de la altura de ésta a la cornisa, que arroja una altura de $1,10 \mathrm{~m}$. La conjunción de estos elementos, en el templo de Clunia, define un ángulo de $45^{\circ}$ con la vertical del entablamento, de modo que la cubierta se proyecta en la misma medida. Para obtener la altura del frontón sin la sima, en la Maison Carrée de Nîmes se divide la longitud de la cornisa ( $\sin$ sima) por 6. Para rematar la cubierta sólo faltaría añadir la altura de la sima. 


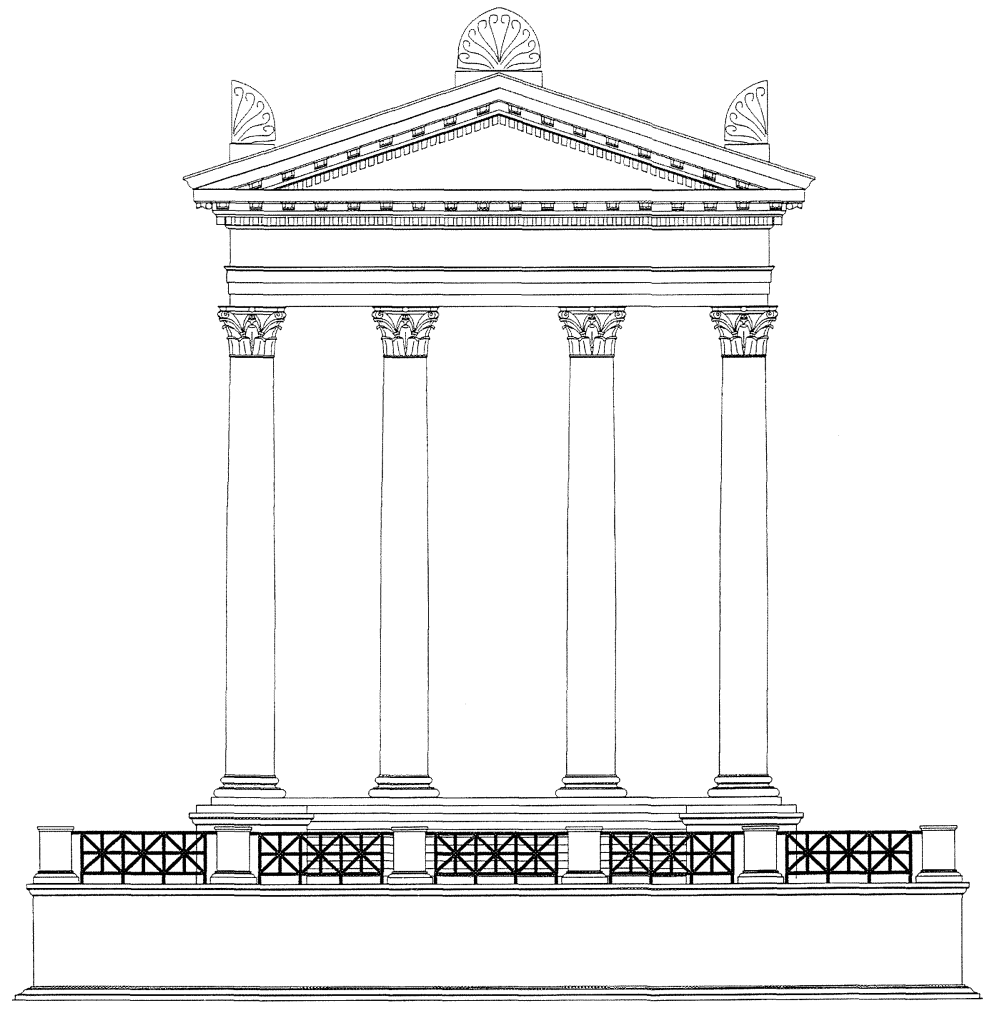

Fig. 15.-Propuesta de restitución del alzado.

basado en el diámetro de la columna con o sin estuco $\left(3 \frac{1}{2}\right.$ o $\left.3 \frac{1 / 4}{p}\right)$. Vemos por ejemplo que entre los $42 \mathrm{p}$ de ancho del podio y los $63 \mathrm{p}$ de ancho de la plataforma existe una relación de $1^{1 / 2}$. Ambas cifras son un múltiplo de $3 \frac{1}{2} \mathrm{p}$. Da la impresión que el módulo de planteo general se base en dicha cifra. De hecho, con el diámetro de 3 1/2 se obtiene una altura final muy próxima al ancho de la plataforma. Sin embargo para obtener esta dimensión, se habría usado una columna con un núcleo inferior, que por lo tanto habría tenido que ser tallada según otras proporciones de las que les serían propias y soportar un entablamento y una separación que no serían los adecuados.

En cambio, con una modulación basada en $31 / 4 \mathrm{p}$, la distribución de las columnas resulta más elegante (fig. 15) y además, se habría obtenido una altura final cercana a los $63 \mathrm{p}$, el ancho de la gran plataforma sin contar las molduras. Una cifra que además de estar rela-

tar delatando la distribución antigua de las plataformas (fig. 14). En vista de los datos recogidos ${ }^{64}$, resulta tentador redondear en $14 \mathrm{p}$ la altura del podio, con dos niveles de alturas tal vez ligeramente diferentes.

Al término de este procedimiento de tanteo, tenemos la sensación de no hallarnos muy lejos de los planteamientos globales del templo. Máxime cuando comprobamos que la base de la plataforma y la altura total del edificio con podio también quedan proporcionadas ya que dibujan aproximadamente un cuadrado. Existiría sin duda una relación entre la planta y el alzado, en dos aspectos: la proporción del propio edificio templar y la relación entre éste y el podio. El primero vendría dado por las proporciones del orden, pero el segundo, que incluye la altura de la plataforma sería específico para cada caso.

Restaría por meditar sobre el módulo aplicado,

${ }^{64}$ Actualmente la cota mas elevada del macizo se encuentra a 3,70 $\mathrm{m}$ del arranque de la moldura inferior del podio. Son unos casi 13 p pero desde luego habrá que contar con el desgaste y con la ausencia de elementos de revestimiento y pavimentación, para poder apreciar hasta que altura llegaba el podio o el suelo de la pronaos en el caso de que existiera un último escalón entre ambos. La plataforma intermedia se situaría tal vez algo más arriba de a la mitad de dicho alzado. Concretamente a una altura mínima de $2 \mathrm{~m}$. cionada con el ancho podio, también se puede entender como la suma de 18 módulos de $3 \frac{1}{2} \mathrm{p}$. El conjunto entonces podría entenderse como un sistema donde la plataforma mediría 4 módulos, la columna 10 módulos y el entablamento más el frontón, nuevamente 4 módulos de $31 / 2 \mathrm{p}$. La altura del templo sería de 14 módulos de 3 1/2 p aunque en realidad, se habría desarrollado a partir de unos 15 módulos de $31 / 4 \mathrm{p}$. Si esto fuera cierto, estaríamos delante de una combinación de dos sistemas modulares que tampoco debería sorprender porque en realidad el replanteo general no tiene por qué condicionar el módulo aplicado al alzado del orden.

Ciertamente las mediciones de las que partimos están lejos de ser precisas y se han tomado determinadas opciones, como la proporción de la columna o del entablamento, en última instancia de forma arbitraria. Quedaría además por resolver el problema del efecto de achatamiento producido por la adición de las acanaladuras a un fuste cuya altura se ha calculado en función del diámetro del núcleo sin revestimiento. Todo ello, unido a que la apreciación de los módulos sólo puede proceder de un análisis detallado de todos los elementos, significa que, tal como apuntábamos, no estamos haciendo más que una restitución que pretende ser expresiva. 